\title{
Short-Term Creep-Rupture Behaviour of AISI 310S Austenitic Stainless Steel Sheets Manufactured in Salem Steel Plant, a Special Steels Unit of Steel Authority of India Limited, Ministry of Steel, Government of India
}

\author{
A. Kanni Raj \\ Professor, School of Freshman Engineering, Vel Tech Rangarajan Dr.Sagunthala R\&D \\ Institute of Science \& Technology, Chennai, India \\ E-mail: ncmde17@psncet.ac.in
}

\begin{abstract}
The creep behavior of AISI 310 S stainless steel taken from SAIL's Salem stainless steel plant has been investigated by constant load tensile creep test at the temperatures of 973, 1023, and $1073 \mathrm{~K}$ and loads of 66.6, 74.8, 86.6, and 94.8 MPa. It exhibits steadystate creep behavior in most test conditions. The double logarithm plot of rupture life and applied stress yielded straight lines at all the three test temperatures indicating that power-law creep due to dislocation climb is the operating mechanism of creep deformation. Linear relationship was obtained for plots of logarithm of rupture life against inverse temperature obeying Arrhenius type of temperature dependence with activation energy of $340 \mathrm{~kJ} / \mathrm{mol}$. The stress-rupture data yielded a master curve of Larson-Miller parameter. The plot of Monkman-Grant relationship is typical indicating that rupture is controlled by growth of grain boundary cavities. The metallographic examination of crept samples revealed formation of grain boundary voids and cracks leading to intergranular creep fracture. Deformation twins and carbide precipitates were also observed. Creep-rupture properties are compared with that of AISI 600 ironbased superalloy to analyze quantitatively its behavior.
\end{abstract}

Keywords: Creep, Stress-rupture, AISI 310S Stainless Steel, AISI 600 Superalloy

\section{Introduction}

Materials operating at high temperature are subjected to creep, hot corrosion, erosion, and phase change which severely affect the temperature capability and load bearing capacity of materials [1-3]. AISI 310S stainless steel contains higher chromium and nickel content than common iron-based alloys [4-8]. It is a standardized high-temperature steel for use at temperatures of up to $1323 \mathrm{~K}$ in dry air. It has a unique combination of high strength and superior oxidation resistance for application up to $1323 \mathrm{~K}$. It is also very ductile and has good weldability enabling its widespread usage in many applications. It finds wide application in all high-temperature environments where scaling and corrosion resistance, as well as 
high temperature strength and good creep resistance, are required. Because of its superalloy properties, this alloy is a likely candidate material for high-temperature applications. It is a nonmagnetic alloy that cannot be hardened by heat treatment. It has forming capabilities similar to that of AISI 304 stainless steel. It can be easily formed into most shapes [9]. Extended capabilities of this stainless steel, beyond that of conventional stainless steels, make it potentially viable to replace nickelbased superalloys. A quantum of information connected with processing, tensile properties, oxidation, and hot corrosion properties of this alloy is available in the literature [7]. This academic dissertation project focuses on the creep-rupture behaviour of sheet samples taken from production run of Indian public sector stainless steel giant SAIL's Salem Steel Plant (SAIL stands for Steel Authority of India Limited, Ministry of Steel, See Figure 1) [9]. AISI 310S stainless steel flat rolled coil is primarily used for high-temperature situations (Figure 2). So, the alloy in the form of $1 \mathrm{~mm}$ thick sheets was used in the tests. Further, a comparison of creep data of this alloy with those of an iron-based superalloy AISI 600 is presented, as it is also a candidate material for jet engines and steam turbines [1013].

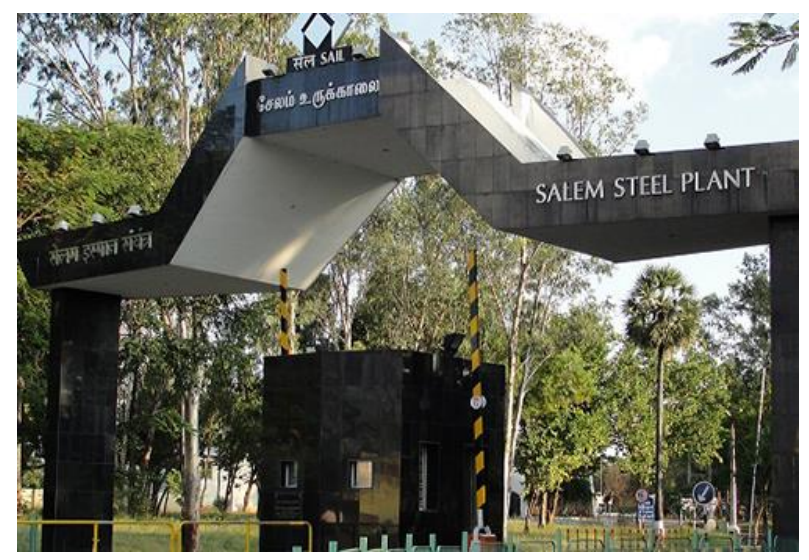

Figure 1. Salem Steel Plant owned by SAIL, Ministry of Steel, India

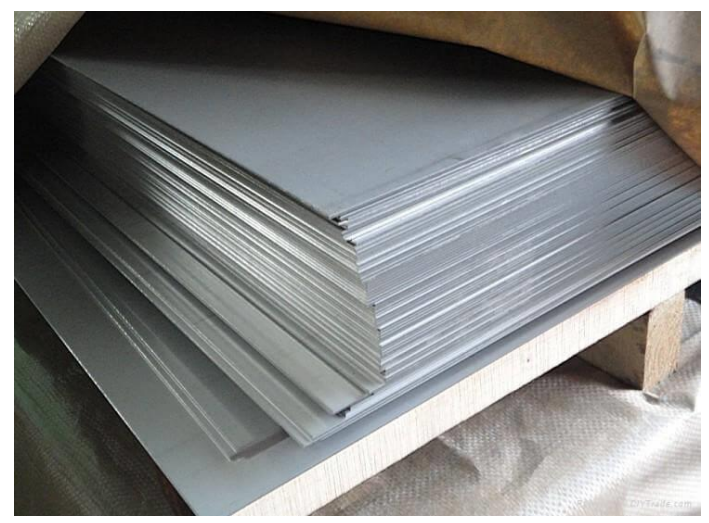

Figure 2. AISI 310 S flat coils used for High Temperature Components 


\section{Materials and Methods}

The materials investigated in creep rupture have the nominal composition of AISI $310 \mathrm{~S}$ stainless steel. The alloy sheet was cut into $10 \mathrm{~cm} \mathrm{X} 10 \mathrm{~cm}$. The sheets were solutionised at $1323 \mathrm{~K}$ for 2 hours in the furnace of Mayes creep testing machine and quenched in water (Figure 3). Soaking time is sufficiently high to ensure uniformity of temperature. It is 12 times higher than that required for mild steel sample of same thickness. This treatment ensures that all carbides are in solution. The composition was obtained using spectrometer. The specimens were longitudinally mid-sectioned, polished by conventional polishing techniques, and etched. The etched specimens were examined by optical microscopy. Creep specimens $1 \mathrm{~cm}$ gauge width and $10 \mathrm{~cm}$ gauge length were machined from the heat treated pieces that correspond to ASTM E8M subsize specifications (Figure 4).

All creep specimens were produced out of the centre of plates transverse to rolling direction. Creep tests were carried out in air at temperatures $973-1073 \mathrm{~K}$ in stress range 60-100 MPa in a Mayes constant load creep testing machine. Test temperature $(\mathrm{T})$ was controlled by means of three PtRh-Pt thermocouples and kept constant at $\pm 1{ }^{\circ} \mathrm{C} / \mathrm{K}$ by means of three PID control units. For creep measurement, the specimens were equipped with a double-coil extensometer, and the creep behavior as specimen elongation was registered continuously. The resolution was about $0.001 \mathrm{~mm}(1: 1250)$. Loading took place in normal atmosphere (air) via lever arm (1:15) using weights. The sample was allowed to soak at test temperature for 1 hour before the test load was applied. A number of different tests have been performed with standard specimens in the usual stress range $(60-100 \mathrm{MPa})$ at temperatures $973-1073 \mathrm{~K}$.

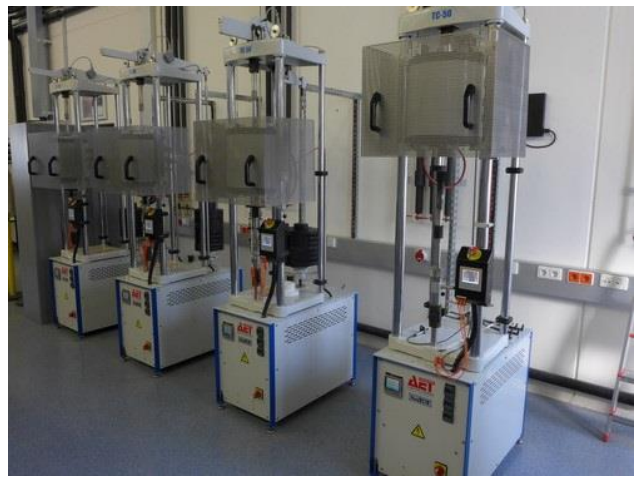

Figure 3. Mayes constant load Mechatronic creep testing machines

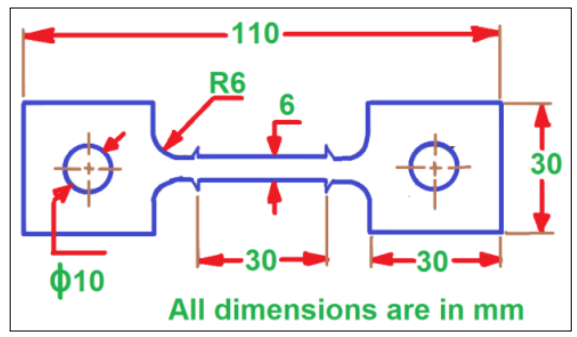

Figure 4. ASTM E8M sub-size specimens used for creep-rupture tests 


\section{Results and Discussion}

The chemical composition was obtained accurately using vacuum evaporation spectrometer of the alloys considered in the analysis (Table 1). Usual optical metallographic procedure was used to get microstructure which consists mainly grain with a grain size of $100 \mu \mathrm{m}$. The microstructure consists of two phases, namely, gamma and carbide phases. Twins are also seen. It is very hard to see distinctly anything at carbides at low magnifications. But optical micrographs clearly reveal the presence of the carbides inside grains. Present test temperatures 973-1073 K and stresses 60-100 MPa fall in power-law creep (dislocation creep) region in deformation map.

Table 1. Chemical composition of AISI 310S stainless steel used in creeprupture research studies along with heat resistant AISI 600 iron based superalloy (superalloy is taken only for comparison purpose)

\begin{tabular}{|l|l|l|l|l|l|l|l|}
\hline Alloys & $\mathrm{C}$ & $\mathrm{Mn}$ & $\mathrm{Si}$ & $\mathrm{Cr}$ & $\mathrm{Ni}$ & $\mathrm{Mo}$ & $\mathrm{Ti}$ \\
\hline AISI 310S & 0.08 & 1.3 & 0.9 & 25 & 19 & 0 & 0 \\
\hline AISI 600 & 0.08 & 1.0 & 1.0 & 15 & 26 & 1 & 2 \\
\hline
\end{tabular}

The region is governed by diffusion-controlled climb-plus-glide processes such as (i) based on lattice diffusion-controlled climb (high-temperature creep), (ii) based on core diffusion-controlled dislocation climb (low-temperature creep), and (iii) transition from climb-plus-glide to glide alone (power law breakdown). Typical creep curves at $973 \mathrm{~K}$ for loads or stress $(\sigma)$ of $66.6,74.8,86.6$, and $94.8 \mathrm{MPa}$ are shown in Figure 5. For the first three loads, all three regions of creep curves such as primary, secondary, and tertiary are available. Well-defined and longer secondary steady-state creep is noted well. But for the highest load, full strains are accumulated only during tertiary stage. Figure 6 shows typical creep curves for 86.5 $\mathrm{MPa}$ for temperatures 973,1023 , and $1073 \mathrm{~K}$. For the first two temperatures, all three regions of creep curves such as primary, secondary, and tertiary are available. Well-defined and longer secondary steady-state creep is noted well. But for the highest temperature, full strains are accumulated only during tertiary stage. Tests were conducted for all the three test temperatures and all the four loads. But for want of avoiding unnecessary discussion, other plots are not shown, and graphs available with full clarity are taken for presentation. The main factor which determines the shape of creep curve besides development of twins and dislocations is investigated here. The factor is creation, coalescence, and growth of creep cavities $[1,10]$. Figure 7 shows the stress dependence of steady-state creep rate for all the three temperatures. The data can be represented by a power law with a stress exponent (n) of -6.5 . Stress exponent (n) of -6.5 is also obtainable from stress versus rupture life (Figure 8). An important significance of this observation is that the steady-state creep rate is controlled by the growth of the cavities nucleated at grain boundaries. Fractographic studies were not carried out, but optical 
metallographic images showed extensive voids. It is interesting to note that the dependence of steady-state creep rate on applied stress can be represented by a power law at all the three temperatures. It helps to obtain $\mathrm{n}$ and activation energy $\left(Q_{c}\right)$. Steady-state creep rate $\left(\dot{\varepsilon}_{s}\right)$ and rupture life $\left(t_{r}\right)$ could be represented by the Expressions (Equations $1 \&$ 2)

$$
\begin{aligned}
& \dot{\varepsilon}_{S} \propto \sigma^{-n} e^{-Q_{c} / R T} \\
& t_{r} \propto \sigma^{n} e^{Q_{c} / R T}
\end{aligned}
$$

Plots were also made to get activation energy. Logarithm of steady-state creep rate against inverse of temperature was used to get activation energy. Was obtained from the plot is $340 \mathrm{~kJ} / \mathrm{mol}$ and is a little higher than the self-diffusion value for gamma iron, that is, $300 \mathrm{~kJ} / \mathrm{mol}$.

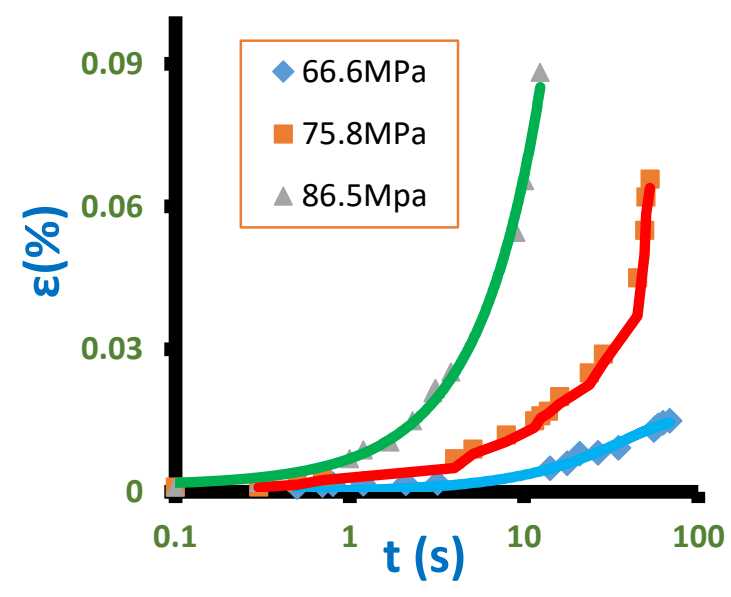

Figure 5. Creep curves at $1023 \mathrm{~K}$

Figure 9 is the plot showing the effect of temperature on steady-state creep rate for stresses 75.8 and 86.5 MPa. Logarithm of steady state creep rate against inverse of temperature was used. Figure 10 is the plot showing the effect of temperature on rupture life for stresses 75.8 and $86.5 \mathrm{MPa}$. Logarithm of rupture life against inverse of temperature was used. $\mathrm{C}=-37.23=$ Intercept of these plots (Enlarged view of one line is given in Figure 11, for getting intercept value on ordinate axis), that is, the value of the constant in Larson-Miller parameter equation. 


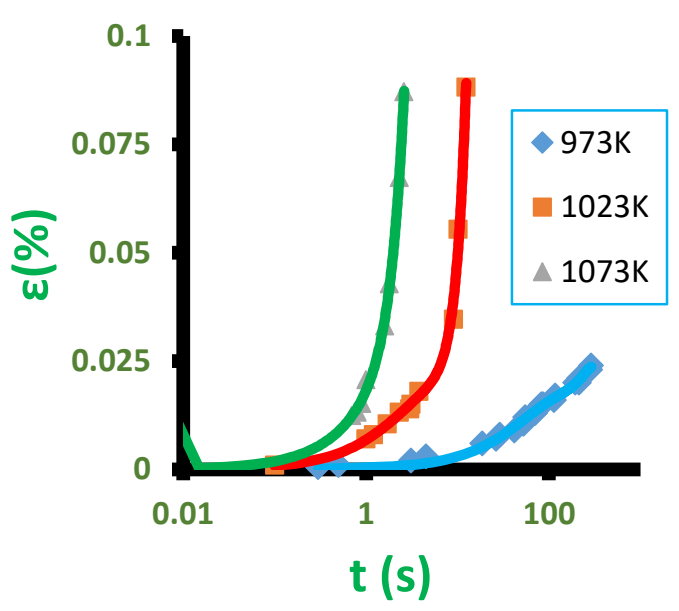

Figure 6. Creep curves for $86.5 \mathrm{MPa}$

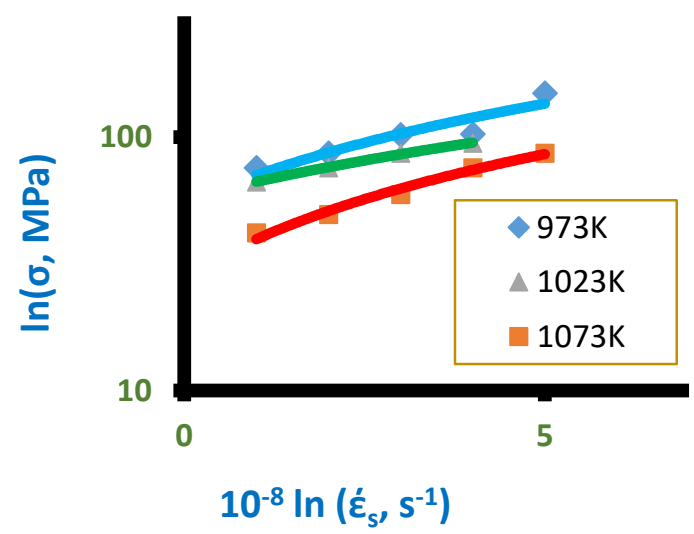

Figure 7. Stress - minimum creep rate at 973-1073 K

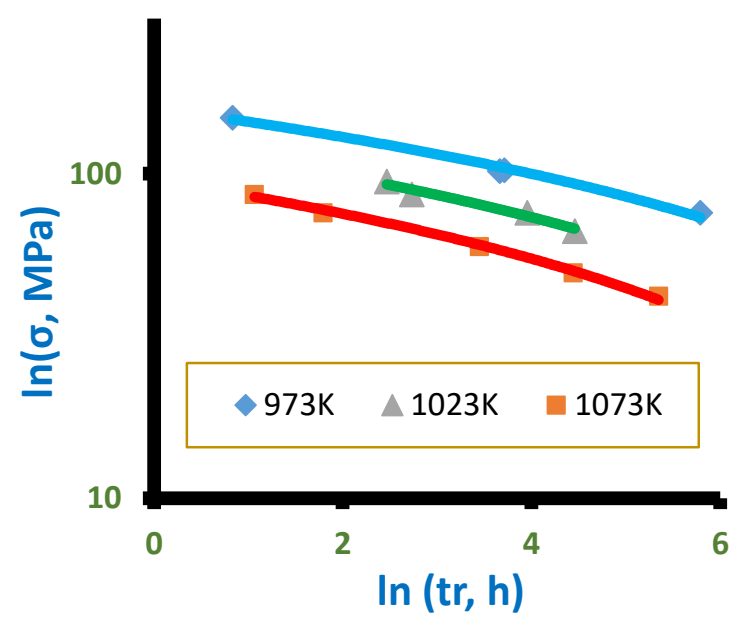

Figure 8. Stress - rupture life at 973-1073 K

One of the most popularly used techniques in representing creep-rupture data is Larson-Miller parameter. This parameter can be derived from the stress and temperature dependence of the creep rate or time to rupture. Figure 12 shows plot of Monkman-Grant relationship (Equations 3 \& 4) 


$$
t_{r}^{m} \dot{\varepsilon}_{s}=c
$$

(3)

$$
m \cdot \ln \left(t_{r}\right)+\ln \left(\dot{\varepsilon}_{s}\right)=\ln (c)
$$

In Equations $3 \&$ 4, $m$ \& c - constants (from our experiments, m=1, c=0.44). This graph is also used as Master-Curve in representing creep-rupture data. The rate equation generally can be written in the form of the Arrhenius type of Equations (Equations $5 \& 6$ )

$$
\begin{aligned}
& P_{L M} \propto T\left[1+\ln \left(t_{r}\right)\right] \\
& P_{L M} \propto T\left[1-\ln \left(\dot{\varepsilon}_{s}\right)\right]
\end{aligned}
$$

The Larson-Miller model is used for experimental tests so that results at certain temperatures and stresses can predict rupture lives of time spans that would be impractical to reproduce in the laboratory (the plot of $\ln \left(t_{r}\right)$ versus $P_{L M}$ is a line (Figure 13)). To further compare the heat-resistant fully austenitic AISI 310S stainless steel with heat-resistant AISI 600 iron-based superalloy, the time to fracture is plotted against applied stress (Figure 14). Superalloy took the longest time to fail more than 3 times to that of the stainless steel. This indicates that solid solution strengthening, dispersion strengthening, and precipitation hardening are not significant compared to superalloy. The microstructures of crept samples compare well with typical of the literature data. For example, typical micrographs are shown in Figure 15, Figure 16 and Figure 17 respectively are crept and fractured specimens after $11.8 \mathrm{~h}$ at $1023 \mathrm{~K}$ for $94.6 \mathrm{MPa}$, ruptured after $86.4 \mathrm{~h}$ at $1073 \mathrm{~K}$ for $66.6 \mathrm{MPa}$, and fractured specimen after $86.4 \mathrm{~h}$ at $1073 \mathrm{~K}$ for $66.6 \mathrm{MPa}$ [9].

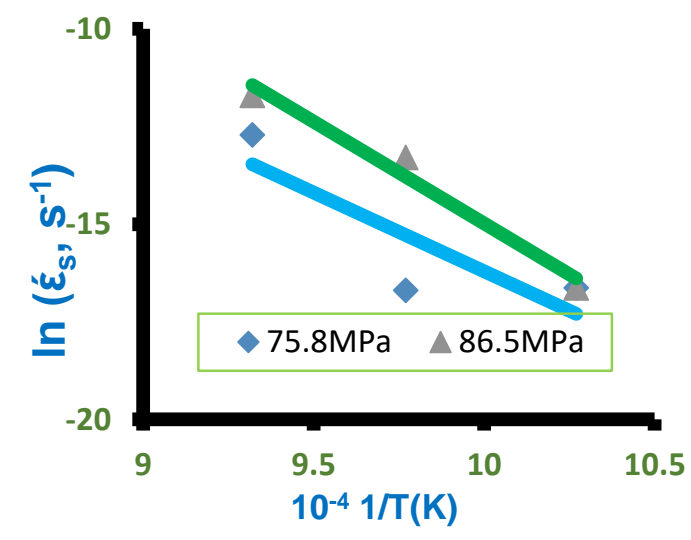

Figure 9. Temperature - minimum creep rate for $75.8 \& 86.5 \mathrm{MPa}$ 


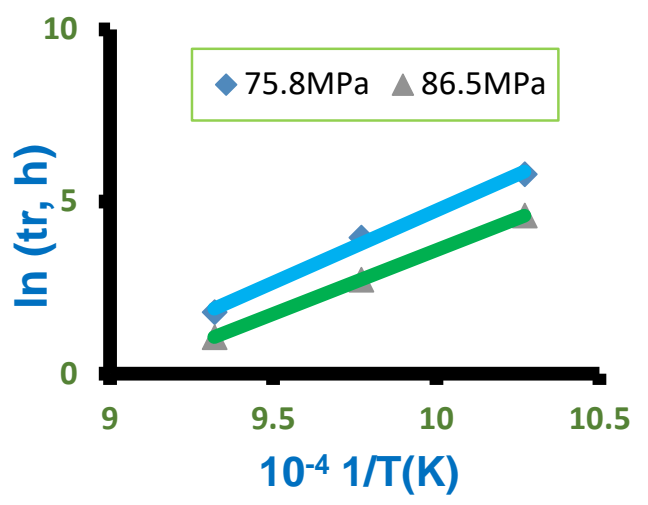

Figure 10. Temperature - rupture life for $75.8 \&$ 86.5 MPa.

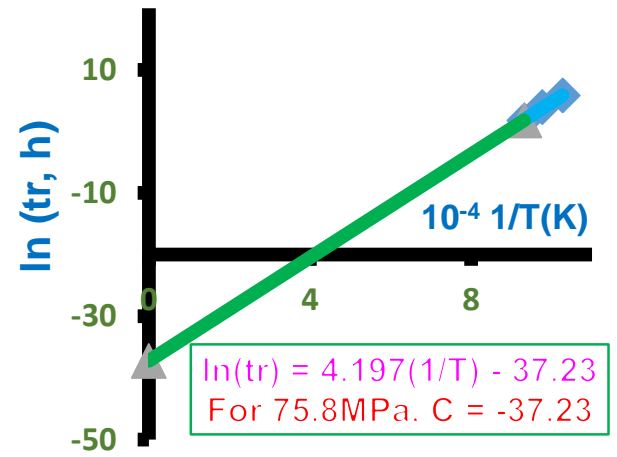

Figure 11. Orr-Sherby-Dorn parameter plot

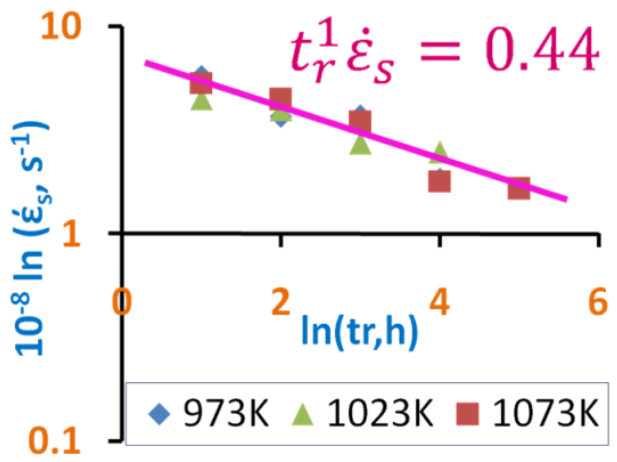

Figure 12. Monkman-Grant relation plot

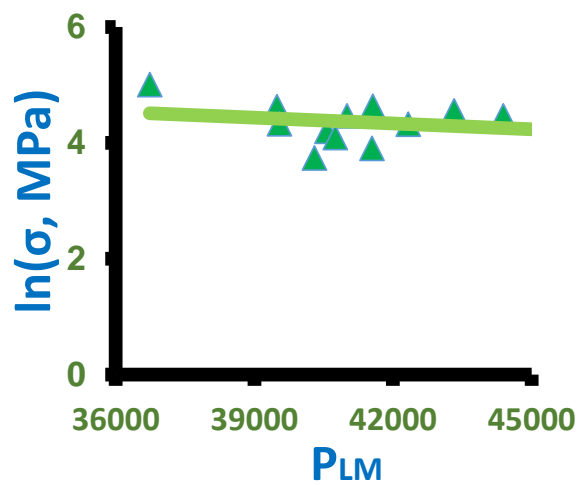

Figure 13. Master Curve at 973-1073K and for 66.6-94.6MPa. 


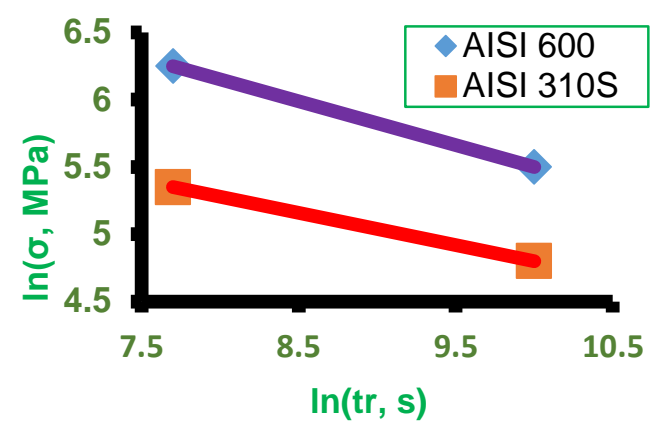

Figure 14. Stress - rupture life at 923 K (with AISI 600 data)

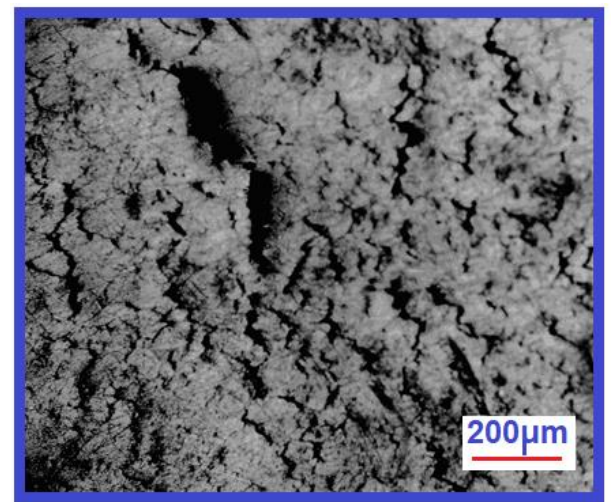

Figure 15. Micrograph of crept sample at $11.8 \mathrm{~h}, 1023 \mathrm{~K} \& 94.6 \mathrm{MPa}$

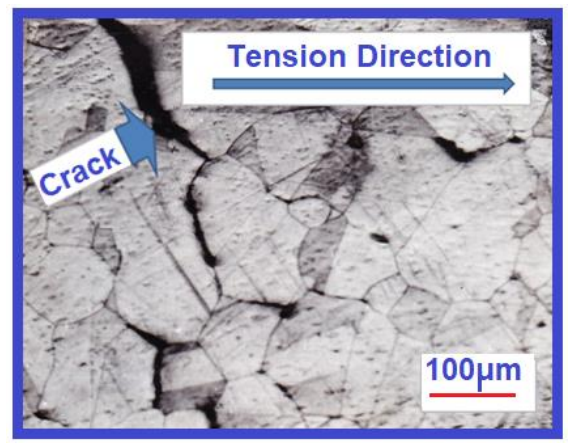

Figure 16. Micrograph of crept sample at $86.4 \mathrm{~h}, 1073 \mathrm{~K} \& 66.6 \mathrm{MPa}$

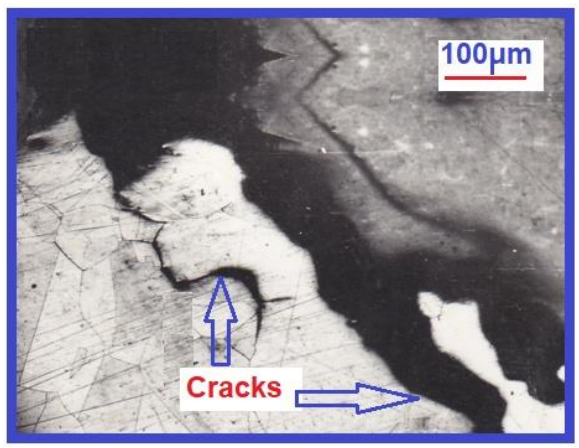

Figure 17. Micrograph of crept sample at $41.1 \mathrm{~h}, 973 \mathrm{~K} \& 102.7 \mathrm{MPa}$ 


\section{Conclusions}

Creep curves were analyzed for stress-dependence at a fixed temperature and for temperature-dependence at a fixed applied load (stress). Creep-rupture followed power law with stress exponent of 6.5 and is matching with earlier data. The activation energy for creep $(340 \mathrm{~kJ} / \mathrm{mol})$ was found to be $10 \%$ higher than for lattice self-diffusion of $\gamma$-iron $(300 \mathrm{~kJ} / \mathrm{mol})$. The stress dependence of steady state creep rate $\left(\dot{\varepsilon}_{s}\right)$ could be represented by a power law of form $\sigma^{-n}$ for all the threes test temperatures $(973 \mathrm{~K}, 1023 \mathrm{~K}$ and $1073 \mathrm{~K})$. On comparison, creep-rupture life of AISI 600 superalloy was found to be 3 times higher. Micrograph showed clearly the intergranular creep fracture. The crack runs perpendicular to load axis.

\section{References}

[1] M.E.Kassner \& R.Ermagan, "Power Law Breakdown in the Creep in SinglePhase Metals", Metals, vol.9, (2019), 1345

[2] S.Yang, W. Lu \& X. Ling, "Spherical indentation creep characteristics and local deformation analysis of $310 S$ stainless steel”, Engineering Failure Analysis, vol.118, (2020), 104946

[3] B.S.Amirkhiz, S.Xu \& C.P. Schott, "Microstructural Assessment of $310 \mathrm{~S}$ Stainless Steel during Creep at $800^{\circ} \mathrm{C}^{\prime}$, Materialia, vol.6, (2019), 100330

[4] A. Kanni Raj, "On High-Temperature Materials: A Case on Creep and Oxidation of a Fully Austenitic Heat-Resistant Superalloy Stainless Steel Sheet", Journal of Materials, vol.2013,(2013), 124649

[5] K. Maruyama, H. Ghassemi Armaki \& K. Yoshimi, "Multiregion analysis of creep rupture data of 316 stainless steel," International Journal of Pressure Vessels and Piping, vol. 84, no. 3, (2017), pp. 171-176

[6] V.Suriyanarayanan \& A. Kanni Raj, "High Temperature Behaviour of $310 \mathrm{~S}$ Alloy”, in Annual Technical Meeting of the Indian Institute of Metals, Calcutta, India, (1995)

[7] A.S.H. Makhlouf \& M. Aliofkhazraei, "Handbook of Materials Failure Analysis with Case Studies from the Chemicals, Concrete and Power Industries", Butterworth-Heinemann, Oxford, UK, (2016)

[8] V.Suriyanarayanan \& A. Kanni Raj, "Creep and Oxidation of 310 S Alloy", in International Conference on Creep, Fatigue and Creep-Fatigue Interaction, Kalpakkam, India, (1999)

[9] Y. Jiao, J.R. Kish, G. Steeves, W.G. Cook, W. Zheng \& D.A. Guzonas, "Effect of Thermal Pretreatment on the Corrosion of Stainless Steel in Flowing Supercritical Water", Journal of Nuclear Engineering and Radiation Science, vol.2, no.1,(2016), 011015

[10] A. Kanni Raj, “On High Temperature Materials: Stress-Rupture Characteristics Of AISI 310S Stainless Steel Sheets at Temperature 973-1073K under Applied Stress 40-150MPa", International Journal of Engineering Applied Sciences and Technology, vol.3, no.9, (2018), pp. 31-36 
[11] A. Kanni Raj, "Aircarft and High Temperature Materials, Aircraft Stress Analysis \& Finite Element Analysis", in Curriculum and Syllabus for B.E.Aeronautical Enginneering, PSN College of Engineering \& Technology (Autonomous), Tiruneveli, India, (2014)

[12] H. De Cicco, M. I. Luppo, H. Raffaeli, J. Di Gaetano, L. M. Gribaudo, and J. Ovejero-Garcia, "Creep behavior of an A286 type stainless steel," Materials Characterization, vol. 55, no. 2, (2005), pp. 97-105

[13] A. Kanni Raj, "Introduction to Aerospace Engineering", in Curriculum and Syllabus for B.Tech.Aeronautical Enginneering, Vel Tech Rangarajan Dr.Sagunthala $R \& D$ Institute of Science \& Technology (deemed to be University), Chennai, India, (2015) 